\title{
Research on the cultivation path of smart home-based care service mode in Internet + vision
}

\author{
Qingchao Peng \\ International Business School, Shaanxi Normal University, Xi'an, Shaanxi, China
}

\begin{abstract}
Home-based care for the aged is an effective method to solve the problem of caring the aged in China. This thesis analyzes some problems existing in the development of current home-based care service for the aged in our country and the positive effects brought by Internet+ in home-based care service. It proposes a new service mode of care for the aged--Internet+ home-based care service, and explains the establishment of this system and the responsibilities of the participants. Also, it explores the path to realize the establishment of Internet+ home-based care service mode so as to promote the healthy development of home-based care service in China.
\end{abstract}

Keywords: Internet+; home-based care for the aged; smart care for the aged; service mode of care for the aged

China is in the era of ageing and the problem of care for the aged has become a hot issue for our government and society to solve today. As home-based care service for the aged is in accordance with our national situation, it has become the main pattern of domestic care for the aged. However, there're many problems existing in current development of home-based care for the aged, especially its health management and informatization which constitute the foundation for information of remote medical care and mobile medical care in the future. In recent years, the rapid development of Internet + information technology has brought opportunities to public service from technical perspective, especially to the career of care for the aged. Hence, how to make use of the development opportunities brought by Internet + and how to create a new service mode of Internet + home-based care for the aged will be the key issues with great attention from academic school and governmental circle for research in the future.

\section{PROBLEMS EXISTING IN THE DEVELOPMENT OF CURRENT HOME-BASED CARE SERVICE MODE}

(1) Mismatching between supply and demand of home-based care for the aged which is inconvenient and inflexible
The unique advantage of home-based care for the aged is its integration of family and community resources of care for the aged. Its offer of one-for-one or many-for-one door-to-door service has obtained recognition from the society and the aged ${ }^{[1]}$ Nevertheless, due to difficult information communication during practice, demands for care of the aged cannot be promptly delivered to day care centers, social workers or volunteers on time, resulting in low convenience and flexibility in care service for the aged. For example, even if the elders succeed in announcing their demands fluently, day care centers have to prepare enough manpower and arrange appropriate time for door-to-door service which are the two main problems often occur in reality. The fundamental reasons for the occurrence of these problems include difficult information communication between the elders' demands in care and the supply of care for the aged from community and unmatched care supply and demand caused by delayed information communication that result in failure of satisfying the elders' demands promptly and on time.

(2) Care service for the aged is narrow in range; little in content; and insufficient in mental concern In current mode of home-based care for the aged, the service types of day care are mainly about material life and are lack of health care and spiritual consolation regardless whether the service is door-to-door care 
provided by personnel with professional training or by daycare centers. On the one hand, day care centers for the aged have little knowledge about each elder people's physical health indicators and are lack of effective measurement and detailed understanding of their demands in spiritual consolation, making it hard to provide precise health management and spiritual consolation service in practice. On the other hand, the elders' demands in health care and spiritual consolation have been gradually increased. However, it's impossible for them to deliver these demands to each nursing worker just once. As a result, their spiritual needs are always lack of satisfaction.

(3) Quality of home-based care service is hard to measure and the management efficiency is low

Current door-to-door service for the aged is as follows: at first, the elders ask for service to community. Then, community will appoint personnel for door-todoor service. In the next step, social workers will provide the service and return to community for filing. It is obvious that this process is incomplete. As a special kind of service, service for the aged shall have quality assurance which requires service assessment and feedback. Hence, new door-to-door service process shall be as follows: at first, the elders ask for service to community. Then, community will appoint personnel for door-to-door service. In the next step, social workers will provide the service and return to community for filing. At last, the elders having received the service will give service assessment and suggestion feedback. Current service process which is lack of assessment and on-time feedback mechanism has made it difficult for community and day care centers to master the quality and effect of service for the aged. Besides, it is also difficult for them to understand the elders' follow-up demands. As a result, current process is bad for assessing social worker's service level. In addition to the lack of clear assessment, training, incentive and management mechanism in community and day care centers, it is hard to improve service personnel's quality and the level of service for the aged.

\section{NEW THOUGHTS ON PROMOTING INTERNET+ HOME-BASED CARE SERVICE DEVELOPMENT}

In recent years, our internet technology has obtained prosperous development. As a result, Internet + has transformed and influenced many industries; and has also brought opportunities to public service, especially service for the aged. ${ }^{[2]}$ By changing information communication and transfer modes, strengthening resource allocation and integration, and improving service management efficiency, Internet + has solved various problems existing in current home-based care service mode. It certainly will provide revolutionary change for the development of home-based care service for the aged. Therefore, the combination of Internet + and home-based care may bring new directions for the healthy development of home-based care for the aged.

\subsection{Core ideas of Internet + home-based care}

The nature of Internet + home-based care is the combination of internet and traditional home-based care service for the aged. It refers to provide comprehensive, convenient, flexible, and timely home-based care service with low cost for the elders by using internet and other information technologies. ${ }^{[3]}$ The core idea of Internet + home-based care is to explore more valuable care service modes for the aged by taking the elders as the orientation and using internet information technologies, so as to better satisfy the elders' various service needs and promote the sustainable healthy development of home-based care service for the aged.

\subsection{Opportunities and positive effects brought by "Internet+" in home-based care service}

Firstly, Internet + home-based care is beneficial to solving the difficulties of information communication in current home-based care for the aged, so as to create better matched home-based care service which is good for improving service convenience and flexibility; comprehensively improving service quality; and promoting sustainable healthy development of home-based care service. To consider from demand perspective, Internet + home-based care can establish electronic social insurance card for each home-based elder people by using information collection, information storage and information spreading functions of internet. It is beneficial for configuration optimization of community supporting resources for elderly. To consider from perspective of supply and demand, Internet + home-based care can establish a community home-based care service information platform by using timely information sharing, information exchange, and big data analysis functions of internet. By timely collecting and updating various demands of the elders, Internet+ home-based care is able to well allocate resources and precisely provide each care service. It can even create conditions for trans-regional resource allocation.

Secondly, Internet + home-based care is beneficial to expanding the items and enriching the content of home-based care service for the aged. To a certain extent, Internet + home-based care can also satisfy the elders' spiritual and cultural demands. In the first place, it is beneficial to expanding traditional daily care service, such as online meal ordering, online shopping, or online request for repair. In the second place, it is beneficial to enriching content of care service. For example, health management system can be exclusively created for the elders based on information 
technology and Internet functions. In the third place, the elders' various demands can be timely collected and given feedback through care service information platform which is good for conducting community activities and satisfying the elders' spiritual consolation. Moreover, spiritual life column and emotional hotline exclusive for the elders can be created based on Internet, in order to promote emotional communication among the elders and improve their spiritual satisfaction. ${ }^{[4]}$

Thirdly, Internet + home-based care is beneficial to forming the closed loop of home-based care service so as to promote continuous quality improvement and improve management efficiency of home-based care service. In the future, community care service information platform will be established through Internet+ and contribute to helping community receive the elders' service demands on time. More importantly, the platform will be able to turn passive into active. It can help change the passive receiving of the elders' service requests into actively provide door-to-door service at regular intervals according to analysis of the elders' each physical index, and thus can greatly improve service quality. Besides, the elders' service request information can be timely collected and processed through the information technology brought by Internet + and they can receive personalized and precise care service. Both the management efficiency of community and social workers' service efficiency can obtain great improvement.

\section{SMART HOME-BASED CARE: PATH TO REALIZE SERVICE MODE OF INTERNET+ HOME-BASED CARE}

\subsection{Establishment of Internet + home-based care service mode system}

Firstly, a basic database system shall be established. Database system lays the foundation for developing Internet + home-based care. A series of basic databases need to be established at the beginning, and thus a systematic home-based care service information platform can be created based on integration of these basic databases which will form the foundation of follow-up care service development. Therefore, big data technology shall be fully applied to establish basic databases under unified planning of the government and through introduction of enterprise cooperation for development of each basic database system. At present, the following basic databases are required in community home-based care service information platform: 1. Database of the elders' basic information; 2. Database of the elders' service demands; 3. Database of the elders' electronic health records; and 4. Database of social resource sharing. Certainly, all these basic databases shall be in mutual communication with social security, civil administration, financial administration, and other related governmental departments, financial institutions, and medical care institutions. The data shall be timely shared and be in mutual intelligibility. Thus, a Five-in-One home-based care service information platform covering provinces, cities, districts, streets and communities can be established.

Secondly, a subsystem of service for the aged shall be established. According to service type, a service subsystem generally includes system of service demand collection and classification, system of life care service management, system of health management and service management, system of community activity management, system of spiritual consolation service management, system of service supervision and assessment, system of community nursing institution management, system of community doctor management, system of community nursing volunteer management, system of governmental pension information release management, emergency call system, risk prevention and control system, and other systems of comprehensive services for the aged. It is obvious that each subsystem needs to burden different services for the aged so as to better meet the elders' needs.

Thirdly, a microscopic operating application system shall be established. After the establishment of basic database system and subsystem of service for the aged is completed, all these systems need to be integrated on a unified community home-based care service information platform for on-site operation. ${ }^{[6]}$ Therefore, a personal operating platform shall be developed to make it convenient for the elders to propose their service demands. In the meantime, a home-based care service operating platform shall also be developed for each nursing subject to provide specific nursing services. These two operating systems need to be unified and integrated on the community home-based service information platform. Real-time exchange and updating of information can be realized through big data analysis and internet interconnection, in order to create a new smart home-based care service mode.

\subsection{Responsibilities of the participants in Internet+ home-based care service mode}

Firstly, the government shall play a leading role. In the first place, the government shall set a development plan of Internet + home-based care in macroscopic level, in order to accelerate the establishment of standard specification system for Internet+ homebased information service platform and improve related laws and regulations. In the second place, establishment of internet foundation shall be consolidated to improve mobile communication network service capability, greatly advance internet access rate, effectively lower internet fee, improve the compensation mechanism of universal telecommunication service, and ensure the interconnection among different information networks. ${ }^{[7]}$ In the third place, financial sup- 
port shall be strengthened. Financial fund from central government shall play a leading role. Power shall be concentrated on supporting development of core big data technology and establishment of public service platform. Financial institutions shall be encouraged to enhance and improve financing service. Support on big data enterprises shall also be enhanced. In the fourth place, cultivation of professional talents shall be strengthened. On the one hand, encourage institutions of higher learning, vocational colleges, and enterprises to cooperate with each other; and enhance practice cultivation of related professional talents. On the other hand, actively recruit volunteers to provide community service for the aged and promote the training on the elders who are healthy and willing to serve others, in order to help arouse those elders' awareness of self-care and self-nursing.

Secondly, introduce enterprises and enhance innovation. In the first place, for basic database development and establishment of home-based care service information platform, , the government shall comprehensively encourage new high-tech internet enterprises to develop community care service management system and operating application system according to actual supply and demand based on the established related standards. Then, the government shall invite public bidding to buy the systems or provide them for the elders and their relatives to use. In the second place, for development of smart software, hardware, and product, the government shall set up a series of policies to encourage high-tech enterprises to develop various smart devices for the elders, such as smart glucometer, smart sphygmomanometer, smartphone, smart shower machine, and related mobile APP, in order to create necessary hardware conditions and thus the elders can enjoy high-quality and convenient nursing service. ${ }^{[8]}$ In the third place, for specific nursing service, encourage related enterprises and community care service management centers to cooperate and create new service modes, in order to provide various door-to-door services for the elders and reach the win-win goal of providing convenient nursing service for the elders and bringing profit to enterprises.

Thirdly, enhance mutual cooperation among social forces. In the first place, recruit and cultivate a batch of professional volunteers to provide service for the aged through community nursing volunteer management system; and establish Electronic Nursing Service Time Bank to create improved reward and punishment mechanism for volunteers so as to promote the prosperous and healthy development of volunteer team. In the second place, actively invite social commonweal organizations to participate in community home-based nursing service information platform and provide colorful artist performance to enrich the elders' spiritual and cultural life. Put mutual assistance and nursing into practice. In the third place, for integration and allocation of community care service resources, in- clude nursing institutions, medical care institutions, enterprises, and public institutions under administration into community home-based nursing service information platform, in order to provide direct and convenient nursing service for the elders living in communities, and to enrich community care service types and modes at the same time. The elders will be able to enjoy high-quality nursing services at home. In short, the three-pronged function of government, market and society shall be fully manifested while three-way-linked mechanism of sound social work, social organization, and community organization shall be established so as to promote the development of Internet + home-based care. ${ }^{[9]}$

\section{CONCLUSIONS}

With the acceleration of ageing in cities, the supply pressure of urban service for the aged will become greater. Internet + has left significant influence on each industry; active introduction of Internet + in homebased care service for the aged is an essential measure to solve the imbalance and unmatched situation in the supply and demand of home-based care service for the aged. Besides, it is beneficial to the exploration of the key role played by Internet + in public service area. However, Internet + home-based care cannot be carried out by any care service subject. It can only be well implemented under the leading and integrated planning of the government; in the collaborative innovation actively participated by enterprises; and with mutual cooperation from all walks of life. Only in this way can the goal to provide timely, convenient, smart and high-quality care service for the aged be reached. Thus, the sustainable healthy development of care for the aged in our country can be promoted.

\section{REFERENCES:}

[1] Pan, F. \& Song, F. 2015. Internet+ community care for the aged: New thoughts on smart care for the aged. Study and Practice, (9): 99-105.

[2] Zhu, Y. 2014. Smart Care for the Aged. Beijing: Social Sciences Academic Press, pp.100-108.

[3] Ning, J.J. 2015. Implementation background, connotation and main content of Internet+ Activity Plan. Electronic Government, (6): 32-38.

[4] Li, G.Y., Zhang, P.Z. \& Sun, J.L. 2015. Big Data Technique and Its Application: Big Data of Smart City. Shanghai: Shanghai Science and Technology Press, pp.18-73.

[5] Bao, Y.T. 2015. Constructing the World of Smart Care for the Aged. Health Management, (2): 30-32.

[6] Xi, H., Ding, Y. \& Zhai, S.G. 2014. Pattern Discussion on the Application of Internet of Things in Long-Term Care System for Disabled Elders. Shandong Social Sciences, (11): 51-57.

[7] Shen, J.L. 2015. Study of the Smart Care System for the Aged in Fuzhou. Academic Review, (3): 126-133. 
[8] Liao, Y.M. \& Qin, Y. 2015. Internet+ health care for the aged: Creating new mode of smart care service for the aged. World Telecommunications, (8): 75-77.
[9] Tong, X. 2015. Development of community care service for the aged to cope with ageing population. Exploration and Free Views, (8): 69-72. 